Research Article

\title{
Estimation of Rock Burst Grades Using Rock Mass Strength
}

\author{
Yalei Wang, ${ }^{1}$ Jinming $X u \mathbb{D}^{1},{ }^{1}$ Junshuai $X u,{ }^{1}$ and Chuanjiang Zhong ${ }^{2}$ \\ ${ }^{1}$ Department of Civil Engineering, Shanghai University, Shanghai 200444, China \\ ${ }^{2}$ China Railway 17 Bureau Group Co., Ltd., Taiyuan 030006, China \\ Correspondence should be addressed to Jinming Xu; xjming211@163.com
}

Received 8 December 2019; Revised 5 April 2020; Accepted 27 April 2020; Published 18 July 2020

Academic Editor: Rafael J. Bergillos

Copyright (C) 2020 Yalei Wang et al. This is an open access article distributed under the Creative Commons Attribution License, which permits unrestricted use, distribution, and reproduction in any medium, provided the original work is properly cited.

The traditional rock burst estimation method is usually based on the $\sigma_{c}$ (rock strength) in practice, while the actual occurrence of rock burst depends more on the structure and strength of the rock mass. In this work, the actual rock bursts occurred in a railway tunnel project in Western China, and the $\sigma_{\mathrm{cm}}$ (rock mass strength) was calculated by the generalized Hoek-Brown criterion. According to the actual situation of rock bursts, a modified rock burst estimation criterion using the ratio of $\sigma_{\mathrm{cm}}$ to $\sigma_{\max }$ (maximum geostress) was proposed. The influence of randomness on the reliability of rock burst estimation criterion was considered. The estimation results based on the traditional and modified method were furthermore compared with those of the actual rock bursts. The results show that $\sigma_{\mathrm{cm}}$ calculated by the generalized Hoek-Brown criterion may be considered well in the rock type and strength, construction condition, and structure features of the rock mass; the estimation results of rock burst using the ratio of $\sigma_{c}$ to $\sigma_{\max }$ are quite different from the actual situation, while those using the ratio of the $\sigma_{\mathrm{cm}}$ to $\sigma_{\max }$ coincided relatively with the actual rock bursts; the ratios of $\sigma_{\mathrm{cm}}$ to $\sigma_{\max }$, which are greater than $0.167,0.066$ to $0.167,0.012$ to 0.066 , and less than 0.012 , are corresponded to the slight, medium, strong, and violent grades of the rock bursts, respectively; the randomness of data selection has certain influence on the rock burst estimation criterion, but the variation range is small; the modified estimation criterion of rock burst proposed in this work has a good reliability. The results presented herein are important for tunnel construction and the prevention of rock burst in the high geostress areas.

\section{Introduction}

When excavating in ground prone to rock burst, it is essential to estimate the intensity of rock burst in order to implement suitable ground control measures. A rock burst is a visible rock mass damage to excavations and represents a major concern in tunneling projects since it is associated with casualties and accidents. This deadly phenomenon initiates in high geostress and brittle rock conditions with extremely complex mechanical features. This may lead to a violent expulsion of rock from the surrounding rock mass. Usually, the rock burst occurs with a sudden release of elastic strain energy in different ways including slabbing, spalling, ejecting, or throwing $[1,2]$.

At present, rock burst is usually estimated based on the $\sigma_{c}$ (rock strength) in practice, and there are many achievements that have been made in this field. For example, Tao [3] proposed a rock burst criterion based on the ratio of $\sigma_{c}$ to $\sigma_{\max }$ (maximum geostress), while Gu et al. [4] proposed a comprehensive criterion for the occurrence of rock burst based on $\sigma_{c}$ and rock integrity. Later on, Zhang and $\mathrm{Fu}$ [5] modified the Tao-Gu criterion. Liu et al. [6] introduced a membership function to investigate the influence of $\sigma_{c}$ on rock burst occurrence. Miao et al. [7] used the Tao discriminant criterion and combined with other rock parameters to comprehensively estimate the rock burst grades. Zhou et al. [8], Li et al. [9], and Afraei et al. [10] regarded the $\sigma_{c}$ as one of the main factors to estimate rock burst intensity. Xue et al. [11] adopted the ratio of $\sigma_{c}$ to geostress as an indicator to estimate the rock burst.

However, the actual occurrence of rock burst depends not only on the $\sigma_{c}$, but also on the structure of the rock mass and the $\sigma_{\mathrm{cm}}$. Rock mass structure, which may change the evolution mode of rock burst activity, is the important factor causing rock burst $[12,13]$ There are also some reports about the influence of rock mass structure on rock burst. For 
example, Zhou et al. [14] found that the rock mass structure plane plays an important role in controlling rock burst and analyzed the mechanism of rock burst caused by the structure plane. Mohamad et al. [15] found that when rock burst occurred, a large number of flying rocks are produced in the rock mass plane with small joint spacing and large aperture. Du et al. [16] recognized that the weakening feature of rock mass structure surface is the main factor to estimate whether rock burst is instantaneous or lagged.

At present, the Hoek-Brown (H-B) strength criterion for calculating $\sigma_{\mathrm{cm}}$ based on rock mass structure is widely recognized. Hoek and Brown [17] gave a nonlinear empirical relationship between the rock mass type, rock mass quality criterion, and $\sigma_{\mathrm{cm}}$. Hoek and Brown [18] obtained the relationship between the ultimate principal stress of rock mass and the rock mass failure through statistical analysis of rock triaxial test data and the rock mass tests. Sharifzadeh et al. [19] calculated the shear strength of rock mass using Hoek-Brown failure criterion and geological strength criterion (GSI). Wu et al. [20] proposed a method to analyze the GSI and the disturbance factor of the rock mass and calculated the RMS based on this method. Ma et al. [21] thereafter estimated the rock burst by a ratio of the $\mathrm{H}-\mathrm{B}$ strength-based $\sigma_{\mathrm{cm}}$ to the horizontal stress perpendicular to the tunnel axis.

The traditional rock burst estimation method usually estimates the rock burst grades based on the ratio of $\sigma_{c}$ to $\sigma_{\max }$, and the estimated results are often different from the actual situation. Nevertheless, the actual rock burst depends not only on the geostress state and the strength of rock, but also on the rock mass structure and the construction disturbance. In this work, the geostress state was determined by the hollow inclusion stress relief method. The $\sigma_{c}$ was obtained by the laboratory uniaxial compressive test. The rock mass structure was characterized by GSI according to the actual situation. The $\sigma_{\mathrm{cm}}$ was calculated by the generalized $\mathrm{H}-\mathrm{B}$ strength criterion. The 18 measurement points were randomly selected from the 22 field measurement points to compare the actual rock burst situation. According to the actual construction situation and rock burst situation, a modified rock burst estimation criterion based on $\sigma_{\max }$ and $\sigma_{\mathrm{cm}}$ was thereafter investigated. The reliability of the modified rock burst estimation criterion was verified by the remaining 4 measurement points, and the influence of randomness of data selection on the stability of the modified rock burst estimation criterion was considered. The research results have important reference value for tunnel construction and determination of rock burst prevention measures.

\section{Measurement of Geostress}

2.1. Engineering Background. The geostress measurements located at the construction site of a railway tunnel in Western China. The measurement area has extremely harsh climate where the mountain ranges extend longitudinally in the north-south direction and the terrain fluctuates greatly. There are many regional great and active faults with frequent earthquakes, high tectonic stresses, and well-developed joints. Due to the fact that the surrounding rock mass is hard and brittle, it is expected that rock burst may occur. The 22 geostress measurements are all taken from the railway tunnel.

2.2. Process of Geostress Measurement. The geostress data were obtained by using the hollow inclusion stress relief method. As shown in Figure 1, a great hole inclined by $3^{\circ}$ to $5^{\circ}$ with a diameter of $130 \mathrm{~mm}$ was drilled during the test. A concentric small hole with a diameter of $36 \mathrm{~mm}$ was then drilled from the bottom of the great hole.

As shown in Figure 2, after completing the small hole, a dry towel was used to wipe the hole and to arrange the adhesion. After mixing the binder, the butter was smeared evenly on the orientation instrument, the surface of the hollow inclusion stress gauge was grinded with sandpaper, the binder was poured into the inner cavity of the stress meter, and the stress gauge was propelled into the borehole with the mounting rod. The entire installation process was controlled within 20 minutes to maintain the fluidity of the colloid.

After the colloid was completely solidified, the inclination and orientation of the borehole, the position of the orifice (earth coordinates), and the mounting angle were measured. As shown in Figure 3, when the stress gauge was released, the data were collected by the YJZ-16+ intelligent digital strain gauge, and the core with the strain gauge is removed. The data are received by the KJ327-F type of the mine pressure monitoring system, and the core with the stress gauge was placed into the confining calibration instrument.

As shown in Figure 4, after gradually applying the confining pressure on the core, the stress-strain curve was obtained and the elastic modulus and Poisson's ratio were thereafter computed.

In this work, the geostress data from the 22 in situ measurement points were used in the later analysis, where 18 of them are randomly selected to compare the actual rock burst situation and estimation results by using the traditional method. The improvement of the traditional estimation method was conducted by analyzing the actual rock burst grades. The correctness of the modified method will be verified by the remaining 4 points. The field results of the $\sigma_{\text {max }}$ of these 18 measurement points and the corresponding laboratory results from the uniaxial compressive tests are shown in Table 1.

\section{Estimation of Rock Burst Tendency}

3.1. Actual Situation of Rock Burst. During the tunnel construction, the appearances of the 18 measurement points are shown in Figure 5.

Five parameters, i.e., motion, sound, aging, impact on construction, and influence depth, were used to comprehensively classify the rock burst grades by the code for hydropower engineering geological investigation (CHEGI), suggested by the National Standards Compilation Group of People's Republic of China [22]. The measurement point 1 


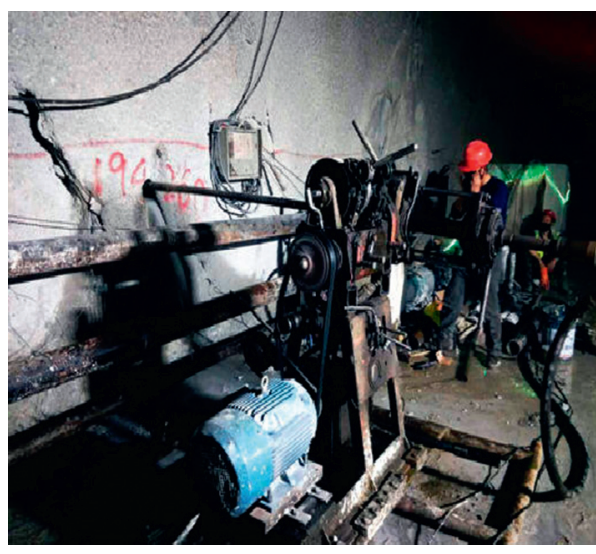

(a)

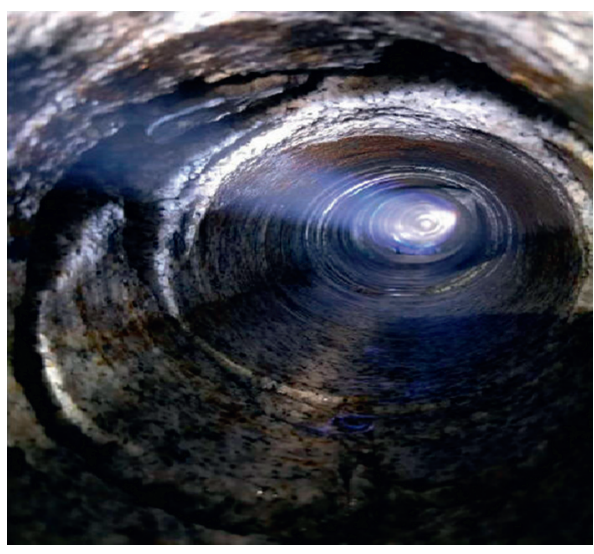

(b)

FIgURE 1: The large hole with a diameter of $130 \mathrm{~mm}$. (a) The large hole drilling process. (b) The appearance of the large hole.

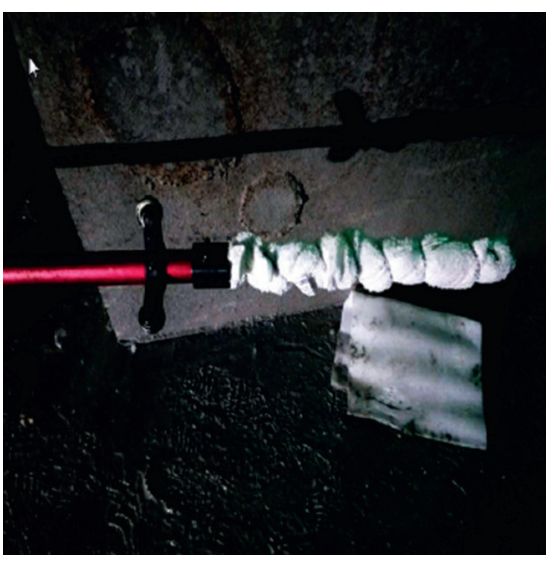

(a)

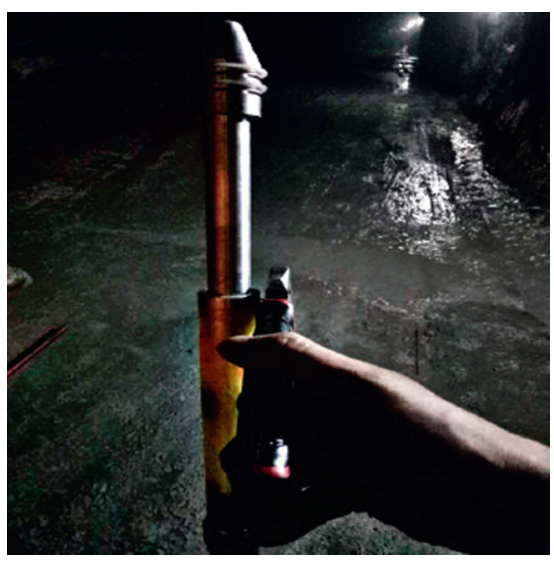

(d)

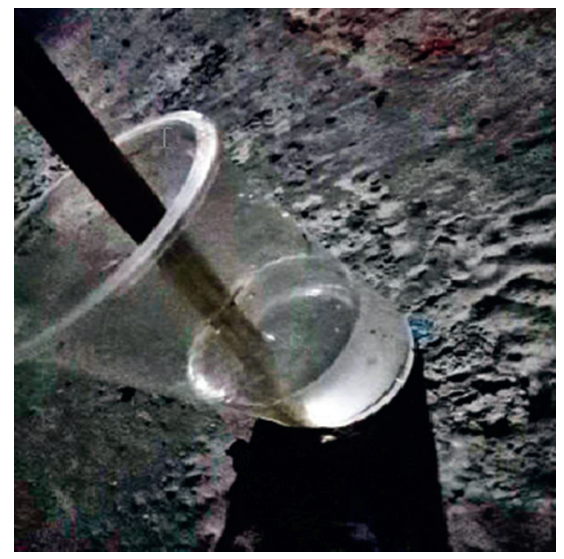

(b)

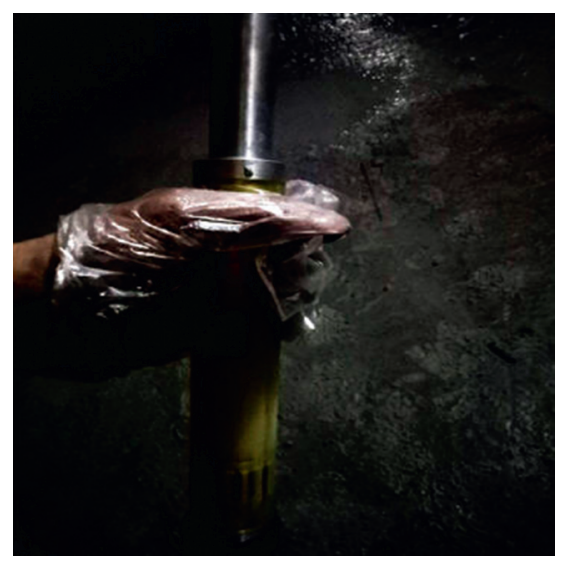

(e)

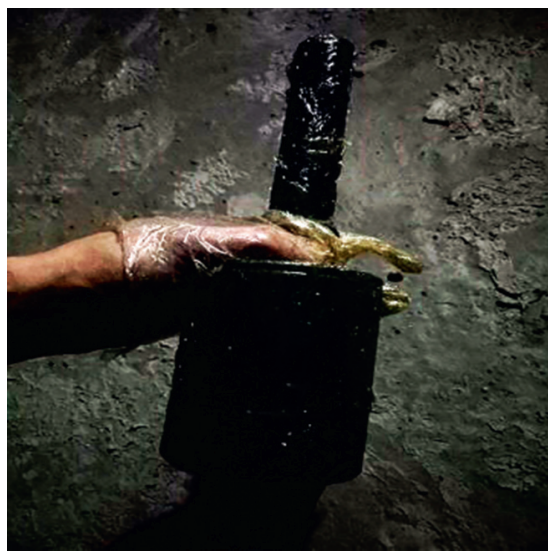

(c)

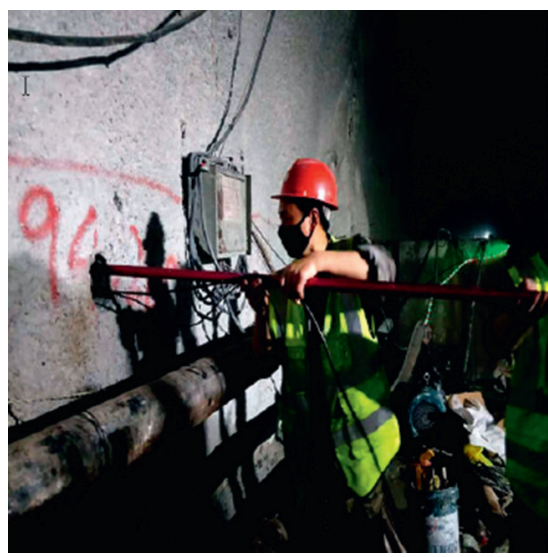

(f)

Figure 2: Stress gauge installation process. (a) Prepare to clean the hole. (b) Mixing glue. (c) Apply butter. (d) Insert pin. (e) Apply glue. (f) Place the stress gauge.

was taken as an example to concisely describe the details in estimating rock burst grade. At the measurement point 1, many large rocks flew out rapidly, accompanied by the rock powder ejection; a strong burst sound was heard; the rock burst lasted for a long time; there is a great influence on the construction of the tunnel; the rock burst pit is distributed 


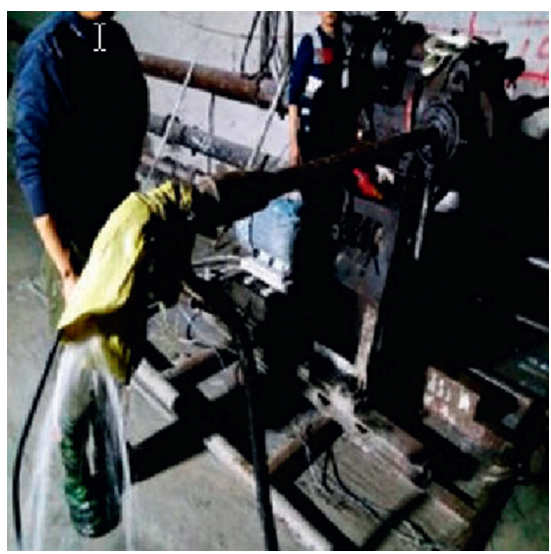

(a)

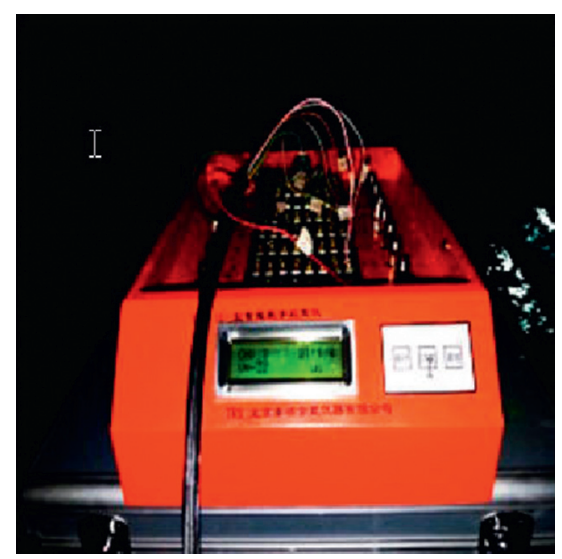

(b)

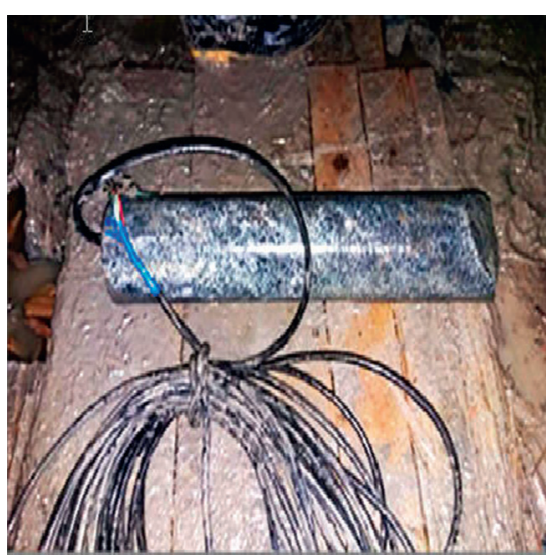

(c)

Figure 3: Stress relief process. (a) Core sampling. (b) Data collection. (c) The core with stress gauge.

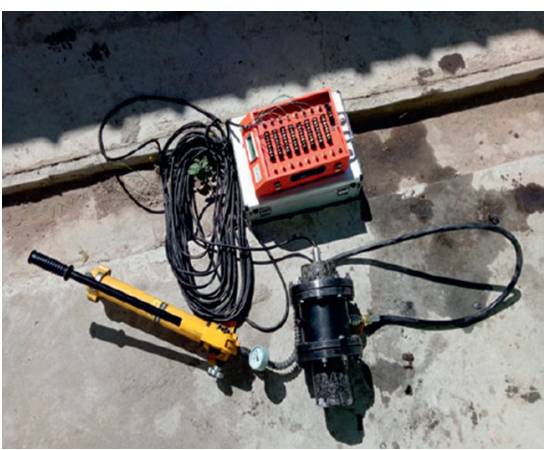

FIgURE 4: Core elastic modulus and Poisson's ratio acquisition.

TABLE 1: $\sigma_{\max }$ and $\sigma_{c}$ at different measurement points.

\begin{tabular}{lcc}
\hline No. of measurement points & $\sigma_{\max }(\mathrm{MPa})$ & $\sigma_{c}(\mathrm{MPa})$ \\
\hline 1 & 49.7 & 40.62 \\
2 & 23.5 & 35.63 \\
3 & 22.2 & 84.54 \\
4 & 34.8 & 30.43 \\
5 & 19.9 & 22.15 \\
6 & 43.3 & 21.08 \\
7 & 31.8 & 26.51 \\
8 & 28.6 & 43.49 \\
9 & 31.0 & 101.27 \\
10 & 33.3 & 62.88 \\
11 & 45.4 & 100.97 \\
12 & 36.6 & 43.15 \\
13 & 48.6 & 123.03 \\
14 & 28.8 & 78.87 \\
15 & 29.6 & 88.76 \\
16 & 28.7 & 41.10 \\
17 & 24.9 & 74.83 \\
18 & 35.8 & 48.40 \\
\hline
\end{tabular}

continuously with the influencing distances of more than $2 \mathrm{~m}$. Therefore, the rock burst at this point was determined at the strong level. Based on the actual situations of rock bursts, the rock burst grades at 18 measurement points were determined by the above method and are shown in Table 2 .
3.2. Rock Burst Estimation Results Using Traditional Criterion. The CHEGI criterion based on the ratio of $\sigma_{c}$ to $\sigma_{\max }$ is often used to estimate the rock burst in practice. The corresponding criterion is shown in Table 3.

In this work, the $\sigma_{\mathrm{cm}}, \sigma_{c}$, and rock burst grades were obtained by using the hollow inclusion stress relief method, laboratory uniaxial compressive tests, and the ratio of $\sigma_{c}$ to $\sigma_{\max }$, respectively. The results are shown in Table 4 . For comparison purposes, the observation results of field rock bursts are also listed in Table 4 . From Table 4, it can be seen that results by using the CHEGI rock burst estimation criterion are quite different from those at the field situations.

3.3. Modified Criterion of Rock Burst Estimation. In the traditional criteria for rock burst classification, the strength in the strength-stress ratio method generally refers to the uniaxial compressive strength. However, the actual occurrence of rock burst in practice relates much with the rock mass structure and the strength of the corresponding rock mass. Therefore, it is necessary to improve the traditional method to pay attention both to the rock mass structure features and to the $\sigma_{\mathrm{cm}}$ in the rock burst estimation.

The rock mass structure features are generally characterized by the geological strength criterion, or GSI. Based on GSI and other relevant parameters (such as the disturbance coefficient and uniaxial compressive strength), the generalized $\mathrm{H}-\mathrm{B}$ strength criterion is often used to calculate the $\sigma_{\mathrm{cm}}$, and the ratio of $\sigma_{\mathrm{cm}}$ to $\sigma_{c}$ may be used as estimation criterion of the rock burst. Therefore, the rock burst estimation based on $\sigma_{\mathrm{cm}}$ will be proposed in the following.

3.3.1. Determination of GSI. The geological strength criterion, or GSI, introduced by Marinos and Hoek [23] and considering the structural features, weathering condition, and the surface features of the rock mass, could better reflect the geological situation of rock mass. As shown in Figure 6, based on the discontinuity, structure, and surface condition of rock mass, the average value of GSI may be estimated. In 


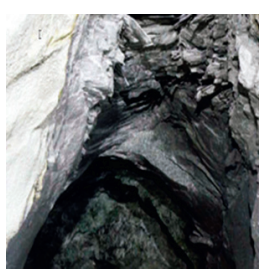

(a)

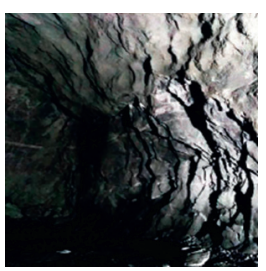

(g)

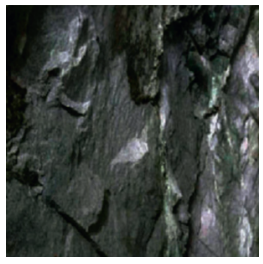

(m)

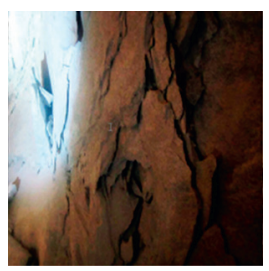

(b)

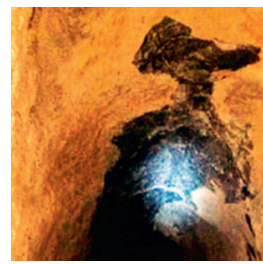

(h)

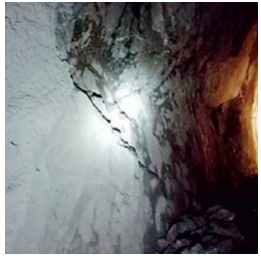

(n)

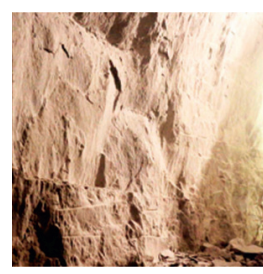

(c)

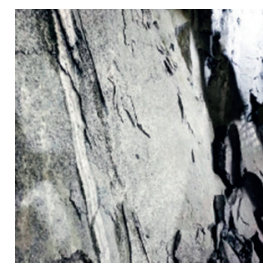

(i)

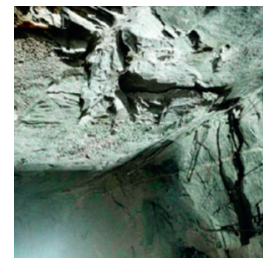

(o)

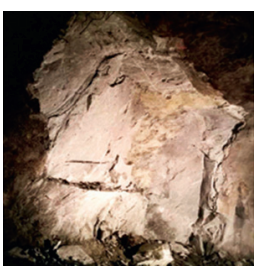

(d)

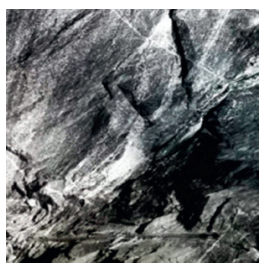

(j)

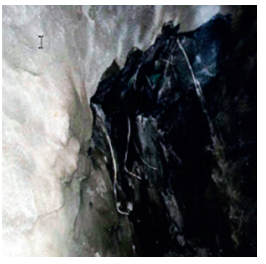

(p)

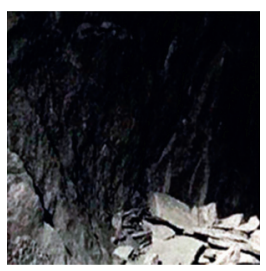

(e)

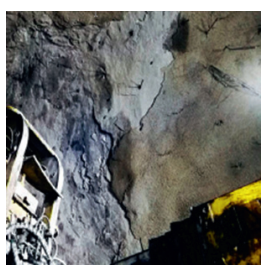

(k)

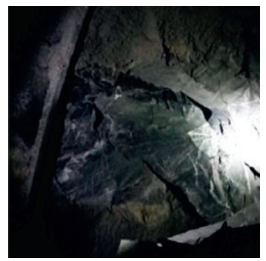

(q)

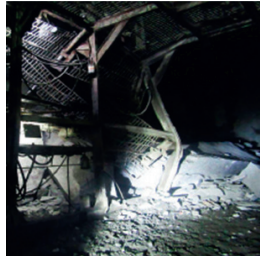

(f)

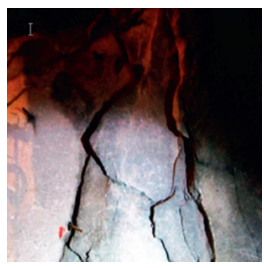

(1)

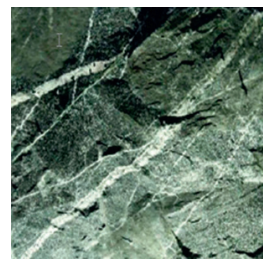

(r)

Figure 5: Appearances after rock bursts at different measurement locations. (a) Point 1. (b) Point 2. (c) Point 3. (d) Point 4. (e) Point 5. (f) Point 6. (g) Point 7. (h) Point 8. (i) Point 9. (j) Point 10. (k) Point 11. (l) Point 12. (m) Point 13. (n) Point 14. (o) Point 15. (p) Point 16. (q) Point17. (r) Point 18.

TABLE 2: Field rock burst grades at different measurement points.

\begin{tabular}{lc}
\hline $\begin{array}{l}\text { No. of measurement } \\
\text { points }\end{array}$ & Rock burst grade \\
\hline 1 & Strong \\
2 & Medium \\
3 & Slight \\
4 & Strong \\
5 & Medium \\
6 & Strong \\
7 & Strong \\
8 & Medium \\
9 & Medium \\
10 & Medium \\
11 & Medium \\
12 & Strong \\
13 & Medium \\
14 & Medium \\
15 & Medium \\
16 & Medium \\
17 & Medium \\
18 & Medium \\
\hline
\end{tabular}

TABLE 3: Rock burst grades using the ratio of $\sigma_{c}$ to $\sigma_{\max }$ in CHEGI criterion*.

\begin{tabular}{lcccc}
\hline \multirow{2}{*}{ Index } & \multicolumn{4}{c}{ Grades of rock burst } \\
& Slight & Medium & Strong & Violent \\
\hline$\sigma_{c} / \sigma_{\max }$ & $4 \sim 7$ & $2 \sim 4$ & $1 \sim 2$ & $<1$ \\
\hline
\end{tabular}

${ }^{*}$ There is no groundwater activity in the area. this figure, "N/A" means that it is not applicable within this range.

As shown in Figure 6, the surface quality of rock mass structure may be divided into five categories using the weathering condition of rock mass and the surface features of joints, which are Very Good, Good, Fair, Poor, and Very Poor. Among them, Very Good means very rough, fresh, and unweathered surface of rock mass; Good means rough, mild weathered, iron surface of rock mass; Fair means medium weathered and altered surface of rock mass; Poor means smooth, highly weathered rock mass surface with a dense overburden or filler or angular fragments; Very Poor means smooth, severely weathered rock mass surface with a soft clay coating or filler. The corresponding range of values is from 100 to 0 in order of high to low, and the higher the value, the better the quality grade of rock mass surface. The structural features of the rock mass are divided into six categories using the order of the integrity of the rock mass structure surface, which are Intact or Massive, Blocky, Very Blocky, Blocky/Disturbed/Seamy, Disintegrated, and Laminated or Sheared. Wherein the Intact or Massive means a complete rock mass or a large rock mass structure with few large spacing and discontinuity; the Blocky means a good and original rock mass structure composed of cubic blocks formed by three mutually orthogonal joint faces; Very Blocky means a partially disturbed rock mass structure, which composed of multifaceted angular blocks formed by at least 4 sets of joints; Blocky/Disturbed/Seamy means a 
TABLE 4: Rock burst grades at various measurement locations using the ratio of $\sigma_{c}$ to $\sigma_{\max }$.

\begin{tabular}{lccc}
\hline No. of measurement points & $\sigma_{c} / \sigma_{\max }$ & Estimated results using CHEGI criterion & Actual field grades of rock burst \\
\hline 1 & 0.82 & Violent & Strong \\
2 & 1.51 & Strong & Medium \\
3 & 3.80 & Medium & Slight \\
4 & 0.87 & Violent & Medium \\
5 & 1.11 & Strong & Strong \\
6 & 0.48 & Violent & Strong \\
7 & 0.83 & Violent & Medium \\
8 & 1.52 & Strong & Medium \\
9 & 3.26 & Slight & Medium \\
10 & 1.88 & Strong & Medium \\
11 & 2.22 & Medium & Strong \\
12 & 1.17 & Strong & Medium \\
13 & 2.53 & Medium & Medium \\
14 & 2.74 & Medium & Medium \\
15 & 2.99 & Medium & Medium \\
16 & 1.43 & Strong & Medium \\
17 & 3.00 & Medium & Medium \\
\hline
\end{tabular}

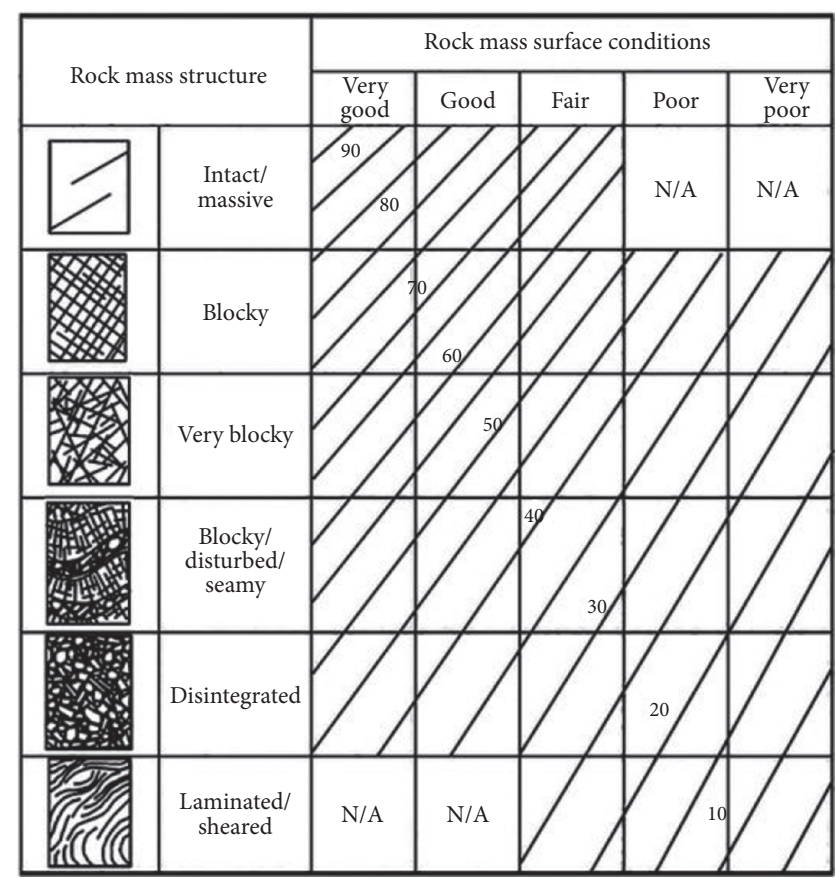

FIGURE 6: Estimation of geological strength criterion [23].

rock mass structure in which a plurality of sets of discontinuous surfaces are mutually cut to form an angular rock mass, and undergoes a fold activity, a layer, or a flank plane continuous; Disintegrated means a severely fractured rock mass, which contains a mixture of angular and circular rock blocks; Laminated/Sheared means the lack of a massive rock mass structure due to the weak schistosity or the close spacing of the shear planes. The corresponding range of values is from 100 to 0 in order of high to low, and the higher the value, the better the integrity of the rock mass.

The Marinos-Hoek method in estimating GSI was used in this work. The measurement point 1 was taken as an example to concisely describe the process in estimating GSI. In the measurement point 1 , the structural fissures and unloading fissures are well developed; the structural fissures are often distributed in an " $X$ " shape; the joints generally do not extend; the fissures are 1 to $10 \mathrm{~mm}$ wide with a maximum width of $15 \mathrm{~mm}$; the fissures are mostly half-open and filled visibly; the joint spacing is more than $2 \mathrm{~m}$. Accordingly, the surface condition of the rock mass at this point was determined as "Good," and the value was estimated as 62; the rock mass structure was determined as a blocky structure with a value of 71 .

As shown in Figure 7, when the intersection of the vertical line of the rock surface condition and the horizontal line of the rock structure characteristic was between the two GSI values, linear interpolation was often used for calculation. Accordingly, the GSI of the measurement point 1 was estimated as 58. According to the above method, the GSI values of the remaining measurement points were estimated, and the estimated GSIs at 18 measurement points are listed in Table 5.

3.3.2. Determination of Relevant Parameters. Other relevant parameters mainly relate to the rock mass disturbance and $\sigma_{c}$. The related parameter of the rock mass disturbance degree is coefficient $D$, which represents the disturbance of the rock mass. Considering the actual situation of the tunnel excavation, $D$ 's of all the measurement points are assumed to be 0.5 . Rock uniaxial compressive strength was determined: the $\sigma_{c}$ at each measurement point is determined by the laboratory uniaxial compression test (see early-mentioned Table 1).

3.3.3. Calculation of Rock Mass Strength Using Hoek-Brown Criterion. Based on Griffith's theory, Hoek et al. [24] investigated the relations between the ultimate principal stress in a rock mass and the rock mass failure from the statistical 


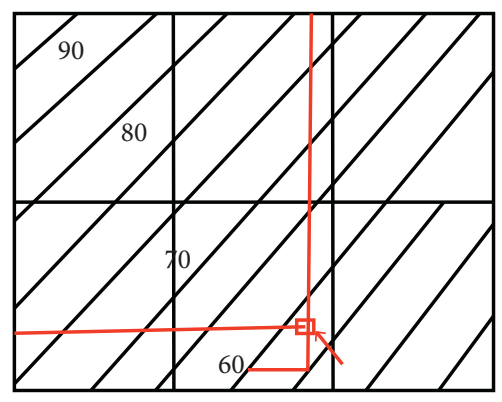

Figure 7: Schematic diagram of linear interpolation.

TABLE 5: GSI at different measurement locations.

\begin{tabular}{lc}
\hline No. of measurement points & GSI \\
\hline 1 & 58 \\
2 & 58 \\
3 & 55 \\
4 & 58 \\
5 & 60 \\
6 & 55 \\
7 & 54 \\
8 & 55 \\
9 & 51 \\
10 & 53 \\
11 & 56 \\
12 & 55 \\
13 & 51 \\
14 & 54 \\
15 & 55 \\
16 & 56 \\
17 & 53 \\
18 & 57 \\
\hline
\end{tabular}

results of the rock triaxial tests and the rock mass tests and obtained the generalized H-B strength guidelines.

In the generalized $\mathrm{H}-\mathrm{B}$ strength criterion, the $\sigma_{\mathrm{cm}}$ is calculated using the following formula:

$$
\begin{aligned}
s & =\exp \left[\frac{(G S I-100)}{(9-3 D)}\right], \\
a & =\frac{[\exp (-G S I / 15)-\exp (-20 / 3)]}{6+0.5}, \\
\sigma_{\mathrm{cm}} & =\sigma_{c} s^{a}
\end{aligned}
$$

where $\sigma_{c}$ is the uniaxial compressive strength of intact rock; $s$ is the empirical parameter reflecting the fracture degree of the rock mass, ranging from 0 to 1 , respectively, taking 0 for the fully fractured rock mass and 1 for the intact rock mass; $a$ is the empirical parameter that reflects the features of the rock mass; GSI is the geological strength criterion of the rock mass; $D$ is a parameter reflecting the disturbance degree of the field rock mass influencing by external factors and ranges from 0 to 1 , respectively, taking 0 for the undisturbed rock mass and 1 for the completely disturbed rock mass; $\sigma_{\mathrm{cm}}$ is the uniaxial compressive strength of the rock mass.
TABLE 6: $\sigma_{\mathrm{cm}}$ at different measurement points.

\begin{tabular}{lc}
\hline No. of measurement points & $\sigma_{\mathrm{cm}}(\mathrm{MPa})$ \\
\hline 1 & 2.42 \\
2 & 2.12 \\
3 & 4.10 \\
4 & 1.47 \\
5 & 1.51 \\
6 & 1.02 \\
7 & 1.20 \\
8 & 2.11 \\
9 & 3.72 \\
10 & 2.66 \\
11 & 5.25 \\
12 & 2.09 \\
13 & 8.42 \\
14 & 3.57 \\
15 & 4.31 \\
17 & 2.13 \\
18 & 3.16 \\
\hline
\end{tabular}

At measurement point 1 , substituting $\mathrm{GSI}=58$ and $D=0.5$ into equations (1) and (2), $s$ and $a$ will be 0.003698 and 0.5033 , respectively. Substituting $s, a$, and $\sigma_{c}$ into equation (3), the $\sigma_{\mathrm{cm}}$ is $2.42 \mathrm{MPa}$. The calculation results of the rock mass strength $\sigma_{\mathrm{cm}}$ of 18 measurement points are shown in Table 6.

3.3.4. Rock Burst Estimation Based on Rock Mass Strength. In computing the ratio of the rock mass strength $\sigma_{\mathrm{cm}}$ to the geostress, $\mathrm{Ma}$ et al. [21] represented the geostress as the horizontal stress perpendicular to the tunnel axis. In the current study, the maximum stress $\sigma_{\max }$ was still used to represent the geostress, considering the availability in practice and the comparability with the existing specifications (i.e., the code for hydropower engineering geological investigation, 2016).

The ratios of $\sigma_{\mathrm{cm}}$ to $\sigma_{\max }$ at different measurement points are listed in Table 7 and shown in Figure 5. The on-site field rock burst grades from the actual observations are also shown in Table 7.

As shown in Table 7, among the 18 randomly chosen points, the number of measurement points for slight rock burst, medium rock burst, strong rock burst, and violent rock burst is $1,11,6$, and 0 , respectively. Because the point number of violent rock burst is zero, it is difficult to accurately determine the extent of the ratio for the violent rock burst. In order to facilitate the division of the rock burst, the ratio of $\sigma_{\mathrm{cm}}$ to $\sigma_{\max }$ is taken as 0 to be temporarily used to estimate the violent rock burst.

From Figure 8, it can be seen that the rock burst is lighter when the ratio of $\sigma_{\mathrm{cm}}$ to $\sigma_{\max }$ is greater, and vice versa. Therefore, three boundary lines may be used to divide the ratio of these measurement points into four parts, corresponding to the grades of the slight, medium, strong, and violent rock bursts. The determination processes of these three boundary lines are as follows: 
TABLE 7: Estimation results of the ratio of $\sigma_{\mathrm{cm}}$ to $\sigma_{c}$ various measurement points.

\begin{tabular}{lcc}
\hline No. of measurement points & $\sigma_{\mathrm{cm}} / \sigma_{\max }$ & Actual grades of field rock burst \\
\hline 1 & 0.0499 & Strong \\
2 & 0.0905 & Medium \\
Slight & Strong \\
3 & 0.1850 & Medium \\
4 & 0.0424 & Strong \\
5 & 0.0762 & Strong \\
6 & 0.0236 & Medium \\
7 & 0.0378 & Medium \\
8 & 0.0738 & Medium \\
9 & 0.1497 & Medium \\
10 & 0.1068 & Strong \\
11 & 0.1157 & Medium \\
12 & 0.0573 & Medium \\
13 & 0.0932 & Medium \\
14 & 0.1241 & Medium \\
15 & 0.1457 & Medium \\
17 & 0.0745 & Medium \\
\hline
\end{tabular}

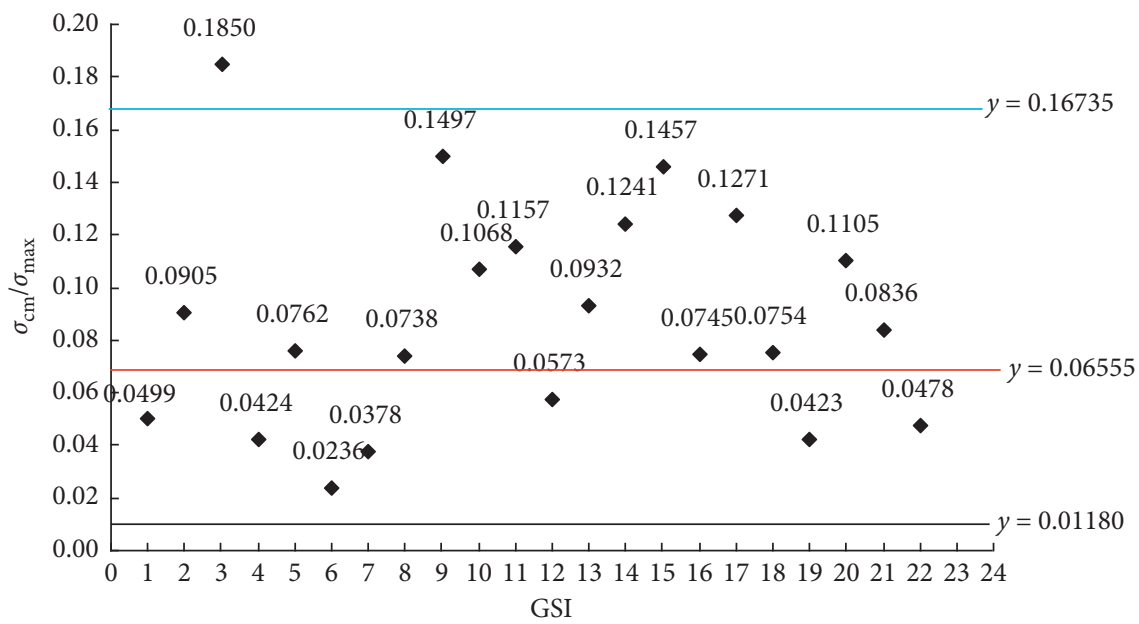

FIgURE 8: The ratios of $\sigma_{\mathrm{cm}}$ to $\sigma_{\max }$ at various measurement points.

(a) The determination of the boundary line between the slight and medium rock bursts. In this case, one and 12 measurement points belong, respectively, to the slight and medium rock bursts. Because $y_{3}=0.1850$ and $y_{9}=0.1497$ represent the minimum and maximum ratios of the slight and medium rock bursts, respectively, at the measurement points 3 and 16, the midvalue of $y_{3}$ and $y_{16}$, or $y=0.16735$, is used as the boundary ratio between these two grades of rock bursts.

(b) The determination of the boundary line between the medium and strong rock bursts. Because $y_{8}=0.0738$ and $y_{12}=0.0573$ represent the minimum and maximum ratios of the medium and strong rock bursts, respectively, at the measurement points 8 and 12, the midvalue of $y_{8}$ and $y_{12}$, or $y=0.06555$, is used as the boundary ratio between the grades of the rock bursts.

(c) The determination of the boundary line between the strong and violent rock bursts. In this case, $y_{6}=0.0236$ and $y=0$ are taken as the minimum and maximum ratios for the strong and violent rock bursts, respectively, at the measurement point 6 and others. The midvalue of $y_{6}$ and 0 , or $y=0.01180$, is regarded as the boundary ratio between the strong and violent rock bursts.

To consider the facility in applications, it is better to transfer these threshold values into ones with three digits after decimal points. Accordingly, the ratio intervals are more than $0.167,(0.066,0.167),(0.012,0.066]$, and no more than 0.012 , respectively, representing the slight, medium, strong, and violent rock bursts. A rock burst estimation method (see Table 8) based on the RMS-to-MG ratio is thereafter obtained.

3.3.5. Verification of Estimation Criterion for Rock Burst. In order to address the reliability of the abovementioned estimation criterion for rock bursts, the remaining 4 field 
TABLE 8: Rock burst estimation criterion based on the ratio of $\sigma_{\mathrm{cm}}$ to $\sigma_{c}$.

\begin{tabular}{lcccc}
\hline Estimation index & Slight rock burst & Medium rock burst & Strong rock burst & Violent rock burst \\
\hline$\sigma_{\mathrm{cm}} / \sigma_{\max }$ & $>0.167$ & $0.066 \sim 0.167$ & $0.012 \sim 0.066$ & $\leq 0.012$ \\
\hline
\end{tabular}

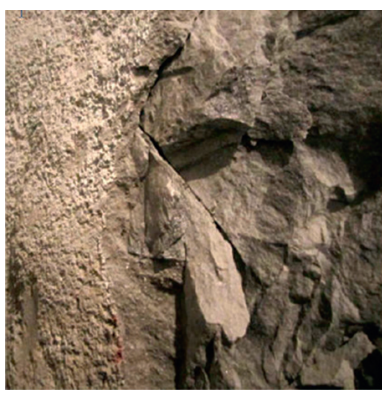

(a)

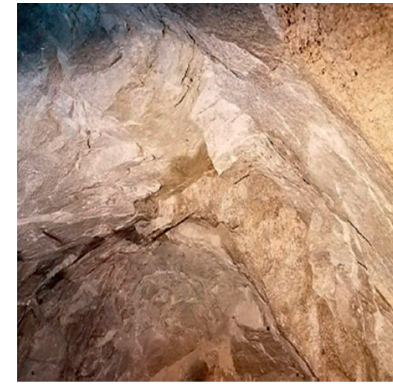

(b)

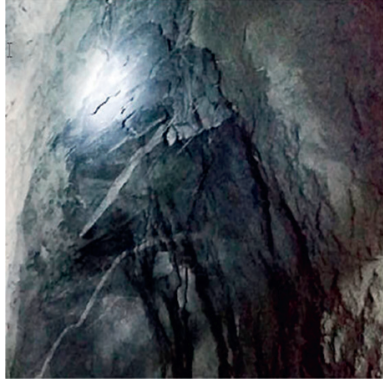

(c)

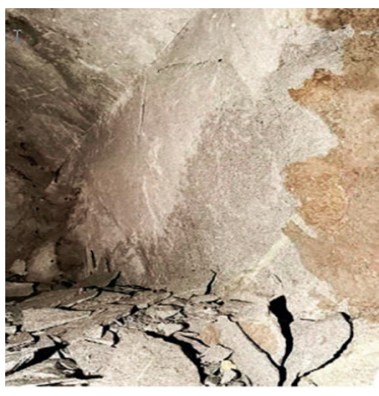

(d)

Figure 9: Appearances after rock bursts at 4 verification measurement points. (a) Point 1. (b) Point 2. (c) Point 3. (d) Point 4.

TABLE 9: Calculation of rock burst grades at 4 verification points using the ratio of $\sigma_{c}$ to $\sigma_{\max }$.

\begin{tabular}{lcccc}
\hline No. of verification points & $\sigma_{c}(\mathrm{MPa})$ & $\sigma_{\max }(\mathrm{MPa})$ & $\sigma_{c}(\mathrm{MPa})$ & Estimated results of CHEGI criterion \\
\hline 1 & 63.97 & 78.7 & 0.813 & Violent \\
2 & 50.37 & 25.4 & 1.983 & Strong \\
3 & 55.39 & 36.9 & 1.501 & Strong \\
4 & 42.54 & 46.3 & 0.919 & Violent \\
\hline
\end{tabular}

measurement points are used for verification. The appearances after the rock bursts at these points are shown in Figure 9.

Using the traditional method based on the ratio of $\sigma_{c}$ to $\sigma_{\max }$, the estimation results at these four verification points are obtained (see Table 9).

Using the modified criterion, the ratios of $\sigma_{\mathrm{cm}}$ to $\sigma_{\max }$ at these four verification points were obtained (see Table 10).

Comparing the index $\sigma_{c} / \sigma_{\max }$ in Table 9 and the index $\sigma_{\mathrm{cm}} / \sigma_{\max }$ in Table 10 with the rock burst grade estimation criteria in Table 3 and Table 8, respectively, the rock burst estimation results of the CHEGI's criterion and modified criterion at four verification points were obtained (see Table 11). Table 11 also lists the field observations.

As shown in Table 11, the estimation results using the CHEGI criterion based on the ratio of $\sigma_{c}$ to $\sigma_{\max }$ are quite different from those in the actual situations; if the criterion based on the ratio of $\sigma_{\mathrm{cm}}$ to $\sigma_{\max }$ is used, the estimation results for the rock bursts will be consistent with the field observations. Accordingly, the rock burst estimation only considering the rock strength regardless of the rock mass structure is not suitable. In the modified criterion, much attention is paid on the rock mass structure in computing the ratio of $\sigma_{\mathrm{cm}}$ to $\sigma_{\max }$. The estimation results based on the modified criterion are consistent with the actual situation and may be used for rock burst estimation.

3.4. The Influence of Randomness of Data Selection on Rock Burst Estimation Criterion. Using the results of 22 field
TABLE 10: Calculation results of $\sigma_{\mathrm{cm}}$ to $\sigma_{\max }$ ratios at 4 verification points.

\begin{tabular}{lcccc}
\hline No. of verification points & GSI & $D$ & $\sigma_{\mathrm{cm}}(\mathrm{MPa})$ & $\sigma_{\mathrm{cm}} / \sigma_{\max }$ \\
\hline 1 & 56 & 0.5 & 3.32 & 0.0423 \\
2 & 57 & 0.5 & 2.80 & 0.1105 \\
3 & 57 & 0.5 & 3.08 & 0.0836 \\
4 & 56 & 0.5 & 2.21 & 0.0478 \\
\hline
\end{tabular}

measurement points, 18 of them were randomly selected to match the actual situation of rock bursts, and a new rock burst criterion was proposed. In order to investigate the influence of the randomness of data selection on the estimation criterion of rock burst, 12 sets of data, each of which includes 18 measurement points, were randomly selected from 22 field measurement points. Using the above method, the corresponding rock burst estimation criteria were obtained and compared. The results are shown in Table 12.

It can be seen from Table 12 that among the estimation criteria of slight rock burst grade in 12 sets, 11 of them are more than 0.167 , and the other is greater than 0.156 , with little change in range; the estimation criterion of medium rock burst grade is 0.066 to 0.167 in 8 sets, 0.062 to 0.167 in 3 sets, and 0.066 to 0.156 in 1 set; the change of estimation criterion of strong rock burst grade is similar to that of medium rock burst grade, with 8 sets ranging from 0.012 to $0.066,3$ sets ranging from 0.012 to 0.062 , and 1 set ranging from 0.019 to 0.066 ; the estimation criterion of violent rock burst grade is no more than 0.012 in 9 sets and less than 0.019 
TABLE 11: Comparison of rock burst estimation results between the CHEGI and modified criterion.

\begin{tabular}{|c|c|c|c|c|c|}
\hline \multirow[t]{2}{*}{ No. of verification points } & \multicolumn{2}{|c|}{$\begin{array}{l}\text { Estimated results of the } \\
\text { modified criterion }\end{array}$} & \multirow[t]{2}{*}{ Determination results of on-site rock burst } & \multicolumn{2}{|c|}{$\begin{array}{l}\text { Estimated results of the } \\
\text { CHEGI criterion }\end{array}$} \\
\hline & $\sigma_{\mathrm{cm}} / \sigma_{\max }$ & Rock burst grade & & $\sigma_{\mathrm{cm}} / \sigma_{\max }$ & Rock burst grade \\
\hline 1 & 0.0423 & Strong & Strong & 0.813 & Violent \\
\hline 2 & 0.1105 & Medium & Medium & 1.983 & Strong \\
\hline 3 & 0.0836 & Medium & Medium & 1.501 & Strong \\
\hline 4 & 0.0478 & Strong & Strong & 0.919 & Violent \\
\hline
\end{tabular}

TABLE 12: Estimation criteria of rock burst grades under different conditions.

\begin{tabular}{lcccc}
\hline \multirow{2}{*}{ No. of sets } & \multicolumn{2}{c}{ Rock burst estimation criterion } \\
& Slight rock burst & Medium rock burst & Strong rock burst & Violent rock burst \\
\hline 1 & $>0.167$ & $0.066 \sim 0.167$ & $0.012 \sim 0.066$ & $\leq 0.012$ \\
2 & $>0.167$ & $0.062 \sim 0.167$ & $0.012 \sim 0.062$ & $\leq 0.012$ \\
3 & $>0.167$ & $0.066 \sim 0.167$ & $0.012 \sim 0.066$ & $\leq 0.012$ \\
4 & $>0.156$ & $0.066 \sim 0.156$ & $0.012 \sim 0.066$ & $\leq 0.012$ \\
5 & $>0.167$ & $0.066 \sim 0.167$ & $0.019 \sim 0.066$ & $\leq 0.019$ \\
6 & $>0.167$ & $0.066 \sim 0.167$ & $0.012 \sim 0.066$ & $\leq 0.012$ \\
7 & $>0.167$ & $0.062 \sim 0.167$ & $0.012 \sim 0.062$ & $\leq 0.012$ \\
8 & $>0.167$ & $0.066 \sim 0.167$ & $0.012 \sim 0.066$ & $\leq 0.019$ \\
9 & $>0.167$ & $0.066 \sim 0.167$ & $0.012 \sim 0.066$ & $\leq 0.012$ \\
10 & $>0.167$ & $0.062 \sim 0.167$ & $0.012 \sim 0.062$ & $\leq 0.012$ \\
11 & $>0.167$ & $0.066 \sim 0.167$ & $0.012 \sim 0.066$ & $\leq 0.019$ \\
12 & $>0.167$ & $0.066 \sim 0.167$ & $0.012 \sim 0.066$ & $\leq 0.012$ \\
\hline
\end{tabular}

in 3 sets; the range of change is a little big, but the probability of occurrence of a situation less than 0.019 is small. Accordingly, the criteria of slight, medium, strong, and violent rock bursts were determined to be greater than $0.167,0.066$ to $0.165,0.012$ to 0.066 , and less than 0.012 , respectively, which have a good stability.

Comparing the data in Tables 12 and 8, it is found that the rock burst estimation criterion obtained in this work has a relatively high stability. It can be seen from Tables 7,10 , and 11 that there is only one slight rock burst measurement point in the 22 field measurement points. If the slight rock burst measurement point was not selected, the maximum ratio of RMS to MG in medium rock burst measurement points will have to be taken as the boundary value between slight and medium rock bursts, which will have a certain impact on these two rock burst estimation criteria. However, the probability of not selecting this slight measurement point from 22 points is $18.18 \%$, so the probability value is relatively small. Moreover, measurement points of the medium rock burst were relatively large, which will weaken this impact to some extent. In the later studies, the accuracy of the boundary value between the slight and medium rock bursts may be modified by increasing the number of slight rock burst measurement points.

\section{Discussions}

(1) Considering the rock mass structure could change the evolution mode of rock burst activity and the rock mass (GSI) degradation could be used for avoiding the risk of rock burst $[25,26]$, the effect of
GSI on the estimation of rock burst grades was explored. The verification point 3 was taken as an example (see Figure 10), where various GSI values $(50,51,52,53,54,55,56,57,58,59$, and 60$)$ were selected.

From Figure 10, it can be seen that the estimation index of rock burst grade increases approximately linearly with the increase in GSI, and $R^{2}$ (goodness of fit) is 0.9916; the effect of GSI on the estimation of rock burst grades is relatively great, and $\sigma_{\mathrm{cm}} / \sigma_{\max }$ increases by $7.1 \%$ when GSI increases by 1 ; the rock burst grade of verification point 3 is strong if GSI is between 50 and 53, while the rock burst grade is medium if GSI is between 54 and 60. Therefore, the effect of GSI on the rock burst grade needs to be paid more attention.

(2) Considering the Hoek-Brown criterion may overestimate the strength of rock mass [27, 28], various methods for estimating rock mass strength were conducted. Taking the measurement point 1 as an example, the values of $\gamma$ (the weight of rock), $Q$ (rock mass quality rating), and RMR (rock mass rating) are $26 \mathrm{kN} / \mathrm{m}^{3}, 0.12$, and 25 , respectively. The estimation results of rock mass strength are shown in Table 13.

From Table 13, it can be seen that the rock mass strength is mainly distributed in the range of 2.4 to $9.0 \mathrm{MPa}$ and 5 to 20 times less than the rock mass strength; the estimations using Hoek's and Kalamaras's methods are relatively close, while those 


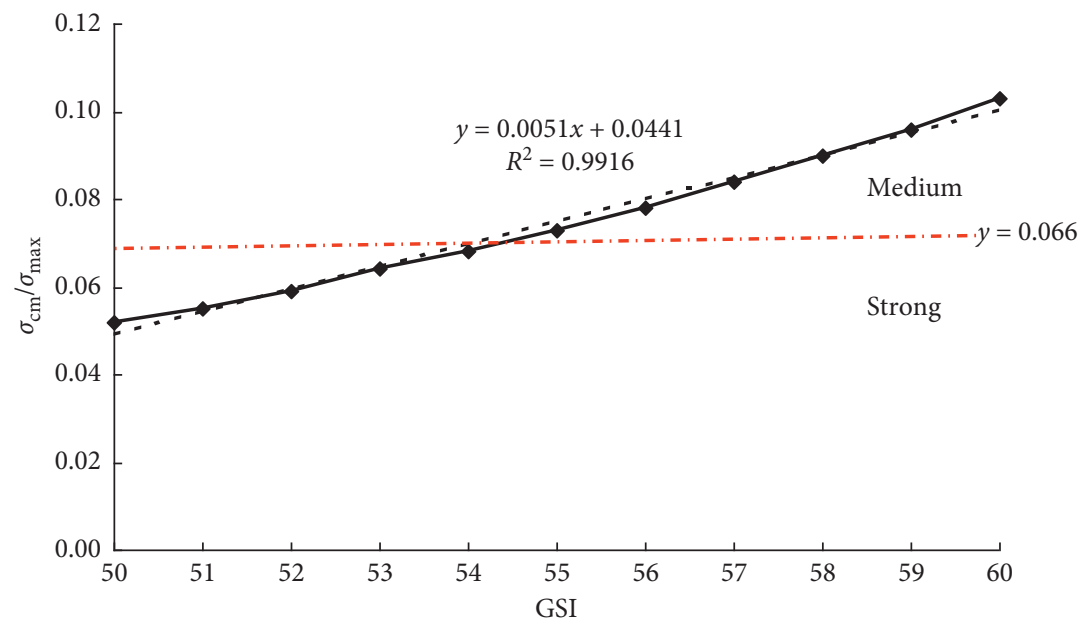

Figure 10: The relationship between GSI and the ratio of $\sigma_{\mathrm{cm}}$ to $\sigma_{\max }$.

TABLE 13: Estimation results of rock mass strength.

\begin{tabular}{lccccccc}
\hline \multicolumn{2}{c}{ Hoek et al. [24] } & \multicolumn{2}{c}{ Barton [29] } & \multicolumn{2}{c}{ Singh [30] } & \multicolumn{2}{c}{ Kalamaras and Bieniawski [31] } \\
Formula & $\sigma_{\mathrm{cm}}(\mathrm{MPa})$ & Formula & $\sigma_{\mathrm{cm}}(\mathrm{MPa})$ & Formula & $\sigma_{\mathrm{cm}}(\mathrm{MPa})$ & Formula & $\sigma_{\mathrm{cm}}(\mathrm{MPa})$ \\
\hline$\sigma_{\mathrm{cm}} / \sigma_{c}=s^{a}$ & 2.42 & $\sigma_{\mathrm{cm}}=0.5 \gamma\left(\mathrm{Q} \sigma_{c} / 100\right)^{1 / 3}$ & 4.75 & $\sigma_{\mathrm{cm}}=0.7 \gamma \mathrm{Q}^{1 / 3}$ & 8.98 & $\sigma_{\mathrm{cm}} / \sigma_{\mathrm{c}}=(\mathrm{RMR}-15) / 170$ & 2.39 \\
\hline
\end{tabular}

using Barton's and Singh's methods seem to be too high. Hence, the rock mass strength estimated by Hoek's method is relatively reasonable.

(3) In order to explore the reliability of the modified method in this paper, the rock burst grade estimation results were compared using various criteria (see Table 14). As can be seen from Table 14, the classification of Barton's criterion, which simply classified the rock burst into the mild and heavy rock burst grades, was not accurate enough; even though Rehman et al. [32] considered the rock is jointed and proposed an index of $S R F_{Q}$, the classification of rock burst was also inaccurate; based on Barton's criterion, Tao [3] divided the mild rock burst into the medium and slight ones, while there is no subdivisions in heavy rock bursts; the rock burst grades were divided into four grades (slight, medium, strong, and violent) by the CHEGI's criterion, but this criterion ignored the effect of the rock mass structure on the rock burst. In the current study, the rock burst grades are divided into four grades using the modified criterion where the rock mass structure was well considered.

The estimation results at four verification points are shown in Table 15. As can be seen from Table 15, the rock burst grades of verification points 1 and 4 estimated by various criteria are relatively consistent, while the rock burst grades at verification points 2 and 3 estimated by Barton's, Rehman's and Tao's criteria are all greater than those estimated by the modified criterion; for these four verification points, the rock burst grades estimated by the CHEGI's criterion are greater (in an one grade) than those estimated by the modified criterion.

Estimated results using various criteria with the actual rock burst were compared and are shown in Table 16.

From Table 16, it can be seen that the estimation results using Barton's, Rehman's and Tao's criteria are overestimated and have a lower accuracy; compared with the actual rock burst results, the estimated ones using the CHEGI's criterion are also overestimated; the estimated rock burst grades using the modified criterion in the current study are in good agreement with the actual ones.

(4) When determining the boundary value of adjacent rock burst grades, it is not enough to consider only the maximum or minimum value of the rock burst grades as the boundary value, and the reliability of the rock burst estimation index obtained by this method is greatly influenced by the factors of artificial selection of data. In this work, the method of taking the midvalue may well consider the data of two adjacent rock bursts, which makes the estimation criterion of rock burst closer to the real value and has better generalization ability. In the future, the boundary value of rock burst grades may be further optimized by increasing the number and diversity of rock burst data.

(5) Taking the Neelum-Jhelum Hydroelectric Project in Pakistan as an example ([12] and [33]), the estimation results using various criteria were compared 
TABLE 14: Various criteria for rock burst estimation*.

\begin{tabular}{|c|c|c|c|c|c|c|c|c|c|c|}
\hline \multirow[b]{2}{*}{$\sigma_{\mathrm{c}} / \sigma_{\max }$} & \multicolumn{2}{|c|}{ Barton's criterion } & \multicolumn{2}{|c|}{ Rehman's criterion } & \multicolumn{2}{|c|}{ Tao's criterion } & \multicolumn{2}{|c|}{ CHEGI's criterion } & \multicolumn{2}{|c|}{$\begin{array}{l}\text { Modified criterion in } \\
\text { this study }\end{array}$} \\
\hline & SRF & Rock burst grade & $\mathrm{SRF}_{Q}$ & Rock burst grade & $\sigma_{\mathrm{c}} / \sigma_{\max }$ & $\begin{array}{l}\text { Rock burst } \\
\text { grade }\end{array}$ & $\sigma_{\mathrm{c}} / \sigma_{\max }$ & Rock burst grade & $\sigma_{\mathrm{cm}} / \sigma_{\max }$ & $\begin{array}{l}\text { Rock burst } \\
\text { grade }\end{array}$ \\
\hline & & & & & $5.5 \sim 14.5$ & Slight & $4 \sim 7$ & Slight & $>0.167$ & Slight \\
\hline $2.5 \sim 5$ & $5 \sim 10$ & Mild & $5 \sim 10$ & Mild & & & $2 \sim 4$ & Medium & $0.066 \sim 0.167$ & Medium \\
\hline$<2.5$ & $10 \sim 20$ & Heavy & $10 \sim 20$ & Heavy & & & $1 \sim 2$ & Strong & $0.012 \sim 0.066$ & Strong \\
\hline
\end{tabular}

${ }^{*} \mathrm{SRF}$ and $\mathrm{SRF}_{\mathrm{Q}}$ are stress reduction factor and modified stress reduction factor, respectively.

TABLE 15: Estimation results of various criteria.

\begin{tabular}{|c|c|c|c|c|c|c|c|c|c|}
\hline $\begin{array}{l}\text { No. of verification } \\
\text { points }\end{array}$ & $\sigma_{\mathrm{c}} / \sigma_{\max }$ & SRF & $\mathrm{SRF}_{Q}$ & $\sigma_{\mathrm{c}} / \sigma_{\max }$ & $\begin{array}{l}\text { Barton's } \\
\text { criterion }\end{array}$ & $\begin{array}{l}\text { Rehman's } \\
\text { criterion }\end{array}$ & $\begin{array}{c}\text { Tao's } \\
\text { criterion }\end{array}$ & $\begin{array}{l}\text { CHEGI's } \\
\text { criterion }\end{array}$ & $\begin{array}{l}\text { Modified } \\
\text { criterion }\end{array}$ \\
\hline 1 & 0.813 & 13.74 & 14.57 & 0.0423 & Heavy & Heavy & Heavy & Violent & Strong \\
\hline 2 & 1.983 & 10.35 & 10.17 & 0.1105 & Heavy & Heavy & Heavy & Strong & Medium \\
\hline 3 & 1.501 & 11.34 & 11.80 & 0.0836 & Heavy & Heavy & Heavy & Strong & Medium \\
\hline 4 & 0.919 & 18.93 & 12.55 & 0.0478 & Heavy & Heavy & Heavy & Violent & Strong \\
\hline
\end{tabular}

TABLE 16: Comparison between actual rock burst grades and estimated results.

\begin{tabular}{lcccc}
\hline Various criteria & Underestimate rate (\%) & Overestimate rate (\%) & Accuracy rate (\%) & Misestimate rate $(\%)$ \\
\hline Barton's criterion & 0 & 50 & 50 & 50 \\
Rehman's criterion & 0 & 50 & 50 & 50 \\
Tao's criterion & 0 & 50 & 0 & 50 \\
CHEGI's criterion & 0 & 100 & 100 & 100 \\
Modified criterion & 0 & 0 & 0 \\
\hline
\end{tabular}

TABLE 17: Comparison of estimation results.

\begin{tabular}{|c|c|c|c|c|c|c|c|c|c|c|c|}
\hline \multicolumn{6}{|c|}{ Rock burst estimation from [29] and [34] } & \multicolumn{2}{|c|}{ CHEGI criterion } & \multicolumn{3}{|c|}{ Modified criterion } & \multirow[b]{2}{*}{$\begin{array}{l}\text { Actual rock } \\
\text { burst grades }\end{array}$} \\
\hline Sr. no & $\begin{array}{l}\text { Chainage } \\
(\mathrm{km})\end{array}$ & Overburden (m) & $\sigma_{c} / \sigma_{\max }$ & $\sigma_{\theta} / \sigma_{c}$ & Rock burst grade & $\sigma_{c} / \sigma_{\max }$ & $\begin{array}{l}\text { Rock burst } \\
\text { grade }\end{array}$ & GSI & $\sigma_{\mathrm{cm}} / \sigma_{\max }$ & $\begin{array}{c}\text { Rock } \\
\text { burst grade }\end{array}$ & \\
\hline 1 & $09+700.00$ & 1200 & 1.49 & 1.80 & Heavy & 1.49 & Strong & 47 & 0.051 & Strong & Heavy \\
\hline 2 & $09+675.30$ & 1245 & 1.47 & 1.83 & Heavy & 1.47 & Strong & 40 & 0.059 & Strong & Heavy \\
\hline 3 & $09+622.66$ & 1380 & 2.56 & 0.86 & Heavy & 2.56 & Medium & 49 & 0.11 & Medium & Slight \\
\hline 4 & $07+970.73$ & 1900 & 1.49 & 1.60 & Heavy & 1.49 & Strong & 63 & 0.171 & Slight & Slight \\
\hline 5 & $07+959.89$ & 1900 & 1.30 & 1.83 & Heavy & 1.30 & Strong & 62 & 0.133 & Medium & Slight \\
\hline 6 & $07+941.71$ & 1900 & 1.42 & 1.68 & Heavy & 1.42 & Strong & 63 & 0.163 & Medium & Slight \\
\hline 7 & $07+937.23$ & 1900 & 1.41 & 1.70 & Heavy & 1.41 & Strong & 62 & 0.150 & Medium & Slight \\
\hline 8 & $07+926.18$ & 1950 & 0.99 & 2.42 & Heavy & 0.99 & Violent & 64 & 0.103 & Medium & Slight \\
\hline 9 & $07+915.57$ & 1950 & 1.34 & 1.78 & Heavy & 1.34 & Strong & 64 & 0.159 & Medium & Slight \\
\hline 10 & $07+910.39$ & 1950 & 1.56 & 1.53 & Heavy & 1.56 & Strong & 65 & 0.204 & Slight & Slight \\
\hline 11 & $07+907.12$ & 1950 & 1.40 & 1.71 & Heavy & 1.40 & Strong & 64 & 0.168 & Slight & Slight \\
\hline 12 & $07+889.00$ & 1950 & 0.84 & 2.84 & Heavy & 0.84 & Violent & 64 & 0.106 & Medium & Slight \\
\hline
\end{tabular}

to further analyze the reliability of the modified criterion. The results are shown in Table 17.

It can be seen from Table 17 that the rock burst estimation grades using traditional criteria are quite different from the actual ones; the estimation results using the modified criterion in this study are much closer to the actual rock burst; the estimation results using the modified criterion have a good reliability for the measurement points with GSI greater than 60 .

\section{Conclusions}

In this work, after using the generalized H-B strength criterion to calculate the $\sigma_{\mathrm{cm}}$, a modified rock burst estimation 
criterion based on the ratio of $\sigma_{\mathrm{cm}}$ to $\sigma_{\max }$ was proposed. The estimation results of this method were compared with those of the traditional method based on the ratio of $\sigma_{c}$ to $\sigma_{\max }$. It shows that

(1) The generalized $\mathrm{H}-\mathrm{B}$ criterion in calculating $\sigma_{\mathrm{cm}}$ may reflect both the structural features of the rock masses and actual situations of the excavation disturbances

(2) The estimation results by using the ratio of $\sigma_{c}$ to $\sigma_{\max }$ in the traditional method are quite different from the actual situation, while the estimation results by using the ratio of $\sigma_{\mathrm{cm}}$ to $\sigma_{\max }$ in this work are consistent with the actual situation

(3) If a ratio of $\sigma_{\mathrm{cm}}$ to $\sigma_{c}$ is used for the rock burst estimation, the ratio intervals in the slight, medium, strong, and violent rock burst grades are more than $0.167,(0.066,0.167],(0.012,0.066]$, and no more than 0.012 , respectively.

(4) The randomness of the selection of rock burst measurement points has a certain influence on the determination of the estimation criterion of rock burst grades, but the overall change of the range is not large. The rock burst estimation criterion proposed in this work has a good reliability.

\section{Data Availability}

The data used to support the findings of this study are available from the corresponding author upon request.

\section{Conflicts of Interest}

The authors declare that they have no conflicts of interest.

\section{Acknowledgments}

Financial supports for the study were provided by the Natural Sciences Foundation Committee of China under Grant no. 41472254 and the Science and Technology Research and Development Program of China Railway Construction Corporation Limited under Grant no. 17-C13. These supports are gratefully acknowledged.

\section{References}

[1] A. C. Adoko, C. Gokceoglu, L. Wu, and Q. J. Zuo, "Knowledge-based and data-driven fuzzy modeling for rockburst prediction," International Journal of Rock Mechanics and Mining Sciences, vol. 61, pp. 86-95, 2013.

[2] A. C. Adoko and T. Zvarivadza, "A bayesian approach for predicting rockburst," in Proccedings of the 52nd U.S. Rock Mechanics/Geomechanics Symposium, Alexandria, VA, USA, June 2018.

[3] Z. Y. Tao, "Rockburst and its evaluation method in high ground stress field," Yangtze River, vol. 18, no. 5, pp. 25-32, 1987.

[4] M. C. Gu, F. L. He, and C. Z. Chen, "Study on rock burst in qinling tunnel," Chinese Journal of Rock Mechanics and Engineering, vol. 21, no. 9, pp. 1324-1329, 2002.
[5] J. J. Zhang and B. J. Fu, "Rock burst and its criteria and control," Chinese Journal of Rock Mechanics and Engineering, vol. 27, no. 10, pp. 2034-2042, 2008.

[6] L. Liu, Z. Q. Chen, and L. G. Wang, "Rock burst laws in deep mines based on combined model of membership function and dominance-based rough set," Journal of Central South University, vol. 22, no. 9, pp. 3591-3597, 2015.

[7] S.-J. Miao, M.-F. Cai, Q.-F. Guo, and Z.-J. Huang, "Rock burst prediction based on in-situ stress and energy accumulation theory," International Journal of Rock Mechanics and Mining Sciences, vol. 83, pp. 86-94, 2016.

[8] K. P. Zhou, Y. Lin, H. W. Deng, J. L. Li, and C. L. Liu, "Prediction of rock burst classification using cloud model with entropy weight," Transactions of Nonferrous Metals Society of China, vol. 26, no. 7, pp. 1995-2002, 2016.

[9] T. Z. Li, Y. X. Li, and X. L. Yang, "Rock burst prediction based on genetic algorithms and extreme learning machine," Journal of Central South University, vol. 24, no. 9, pp. 2105-2113, 2017.

[10] S. Afraei, K. Shahriar, and S. H. Madani, "Statistical assessment of rock burst potential and contributions of considered predictor variables in the task," Tunnelling and Underground Space Technology, vol. 72, pp. 250-271, 2018.

[11] Y. G. Xue, Z. Q. Li, S. C. Li, D. H. Qiu, Y. F. Tao, and L. Wang, "Prediction of rock burst in underground caverns based on rough set and extensible comprehensive evaluation," Bulletin of Engineering Geology and the Environment, vol. 78, no. 1, pp. 417-429, 2019.

[12] W. Z. Chen, C. S. Ma, H. M. Tian, and J. P. Yang, "Discussion on rockburst predictive method applying to TBM tunnel construction," Rock and Soil Mechanics, vol. 38, no. 2, pp. 241-249, 2017.

[13] G. L. Feng, X. T. Feng, B. R. Chen, Y. X. Xiao, and Z. N. Zhao, "Effects of structural planes on the microseismicity associated with rockburst development processes in deep tunnels of the Jinping-II hydropower station, China," Tunnelling and Underground Space Technology, vol. 84, pp. 273-280, 2019.

[14] H. Zhou, F. Z. Meng, C. Q. Zhang, D. W. Hu, F. G. Yang, and J. J. Lu, "Analysis of rockburst mechanisms induced by structural planes in deep tunnels," Bulletin of Engineering Geology and the Environment, vol. 74, pp. 1435-1451, 2019.

[15] E. T. Mohamad, C. S. Yi, B. R. Murlidhar, and R. Saad, "Effect of geological structure on flyrock prediction in construction blasting," Geological and Geotechnical Engineering, vol. 36, no. 4, pp. 2217-2235, 2018.

[16] Y. Du, Y. T. Zheng, M. W. Xie, Y. J. Jiang, and Q. Q. Liu, "Strength weakening characteristic of rock burst structural planes," Chinese Journal of Engineering, vol. 40, no. 3, pp. 269-275, 2018.

[17] E. Hoek and E. T. Brown, "Empirical strength criterion for rock masses," Journal of Geotechnical and Geoenvironmental Engineering, vol. 106, no. 9, pp. 1013-1035, 1980.

[18] E. Hoek and E. T. Brown, "Practical estimates of rock mass strength," International Journal of Rock Mechanics and Mining Sciences, vol. 34, no. 8, pp. 1165-1186, 1997.

[19] M. Sharifzadeh, M. Sharifi, and S. M. Delbari, "Back analysis of an excavated slope failure in highly fractured rock mass: the case study of kargar slope failure (Iran)," Environmental Earth Sciences, vol. 60, no. 1, pp. 183-192, 2010.

[20] L. Wu, A. C. Adoko, and B. Li, "An illustration of determining quantitatively the rock mass quality parameters of the HoekBrown failure criterion," Rock Mechanics and Rock Engineering, vol. 51, no. 4, pp. 1063-1076, 2018.

[21] C. S. Ma, W. Z. Chen, X. J. Tan, H. M. Tian, J. P. Yang, and J. X. Yu, "Novel rockburst criterion based on the TBM tunnel 
construction of the neelum-jhelum (nj) hydroelectric project in Pakistan," Tunnelling and Underground Space Technology, vol. 81, pp. 391-402, 2018.

[22] National Standards Compilation Group of People's Republic of China, GB 50287-2016 Code for Hydropower Engineering Geological Investigation, National Standards Compilation Group of People's Republic of China, Beijing, China, 2016.

[23] P. Marinos and E. Hoek, "GSI: a geologically friendly tool for rock mass strength estimation," in Proceedings of the 2000 International Conference on Geotechnical and Geological Engineering, Melbourne, Australia, November 2000.

[24] E. Hoek, C. Carranza-Torres, and B. Corkum, "Hoek-Brown failure criterion-2002 edition," in Proceedings of the NARMSTAC Conference, Toronto, Canada, July 2002.

[25] P. Konicek, K. Soucek, L. Stas, and R. Singh, "Long-hole destress blasting for rockburst control during deep underground coal mining," International Journal of Rock Mechanics and Mining Sciences, vol. 61, pp. 141-153, 2013.

[26] A. Mazaira and P. Konicek, "Intense rockburst impacts in deep underground construction and their prevention," $\mathrm{Ca}$ nadian Geotechnical Journal, vol. 52, no. 10, pp. 1426-1439, 2015.

[27] P. K. Kaiser, "Underground rock engineering to match the rock's behavior," in Proceedings of the 50th U.S. Rock Mechanics/Geomechanics Symposium, Houston, TX, USA, June 2016.

[28] V. Marinos, P. Marinos, and E. Hoek, "The geological strength index: applications and limitations," Bulletin of Engineering Geology and the Environment, vol. 64, pp. 55-65, 2005.

[29] N. Barton, "Some new q value correlations to assist in site characterisation and tunnel design," International Journal of Rock Mechanics and Mining Sciences, vol. 39, no. 2, pp. 185-216, 2002.

[30] B. Singh, "Indian case studies of squeezing grounds and experiences of application of barton's q-system," in Proceedings of the Workshop on Norwegian Method of Tunnelling, CSMRS, New Delhi, India, September 1993.

[31] G. S. Kalamaras and Z. T. Bieniawski, "A rock mass strength concept for coal seams incorporating the effect of time," in Proceedings of the 8th ISRM Congress, Tokyo, Japan, September 1995.

[32] H. Rehman, A. M. Naji, J.-J. Kim, and H. Yoo, "Extension of tunneling quality index and rock mass rating systems for tunnel support design through back calculations in highly stressed jointed rock mass: an empirical approach based on tunneling data from Himalaya," Tunnelling and Underground Space Technology, vol. 85, pp. 29-42, 2019.

[33] A. M. Naji, M. Z. Emad, H. Rehman, and H. Yoo, "Geological and geomechanical heterogeneity in deep hydropower tunnels: a rock burst failure case study," Tunnelling and Underground Space Technology, vol. 84, pp. 507-521, 2019.

[34] E. Grimstad and N. Barton, "Updating the q-system for NMT," in Proceedings of the International Symposium on Sprayed Concrete Modern Use of Wet Mix Sprayed Concrete for Underground Support, Oslo, Norway, 1993. 